\title{
Collaborative Autoethnography: An Approach to Deliver Learning Objectives of a Community-Engaged Research Course for Health Science Undergraduates during Pandemic Times
}

Angie Mejia

University of Minnesota Rochester,amejiame@r.umn.edu

This is the final submitted version of a text forthcoming in the Fall 2020 edition of Scholarship and Practice of Undergraduate Research (SPUR))

Recommended citation: Mejia, A. Collaborative Autoethnography: An Approach to Deliver Learning Objectives of a Community-Engaged Research Course for Health Science Undergraduates during Pandemic Times. Scholarship and Practice of Undergraduate Research (SPUR), 4(1). [Forthcoming])

Community Collaborative is an upper-division, community-engaged course at the University of Minnesota Rochester geared to health science majors. Each term, several groups of undergraduates collaborate on service-learning or research-based projects for local community agencies working on issues of health. A process was implemented to meet one learning objective in the syllabus (introduction to qualitative data methods) as a response to pandemicimposed limitations on community-engaged learning activities at UMR. The hope was for one group of students to meet these objectives by engaging in a collaborative autoethnography instead of collecting data in the community.

The students and the faculty mentor planned to write, collect, analyze, and synthesize their reflections while conducting a review of autobiographical texts by health-care workers, educators, and researchers writing about their experiences making sense of the COVID-19 impact in their lives and communities. They would then engage in a systematic analysis by focusing on the social dimensions of a pandemic as they relate to different identity positionalities within a health sciences campus. The group met with the faculty mentor several times (at least once a week, sometimes more) to code, interpret, and synthesize more than 10,000 words of reflections (dubbed the "pandemic dataset") according to themes. Also, some students in this group had signed up for additional summer credit hours and wanted to continue working on the project. After the faculty mentor agreed to supervise their summer coursework, the next step was to outline a conference poster/paper with a potential publication to be produced later.

The article was submitted in response to a peer-reviewed journal's call for submissions on anthropological perspectives and analyses on the pandemic. Although it was a lot of work, a collaborative autoethnographic approach allowed the students to meet the course's learning objectives while gaining experience in the manuscript writing process and a deeper appreciation of qualitative research methods. One student stated how "being vulnerable" by writing collectively on the pandemic helped her gain "a shared sense of purpose," not only with members of this group but also other students in similar circumstances. Another student indicated that the process pushed her to critically reflect on her identity as a woman of color and future medical professional in a changing health-care context. Another became more open 
to the possibilities of exploring written work in the medical humanities as a way to balance the more "STEM-focused material" of his fall coursework. Finally, all the students felt that collaborative autoethnography was a positive experience that could benefit their graduating cohort. Some of the students and the faculty mentor received funding from the university to support UMR third- and fourth-year students in creating written and video narratives on their experiences navigating a "pandemic summer." These will be disseminated via social media and archived in the university library's digital repository. 